\title{
CONGENITAL HEMIATROPHY OF THE BRAIN
}

\author{
BY \\ L. CROME \\ From the Fountain Hospital, London
}

(Received for Publication March 13, 1951)

Hemiatrophy of the brain may occur in adults and in old age as a result of degenerative or vascular disorders, but the name is more commonly applied to the congenital or the infantile variety of the condition. It was proposed by Alpers and Dear (1939) that the two varieties be designated secondary and primary respectively. The condition is, however, always secondary in the sense that it is due to some cause which is frequently ascertainable. It is therefore better to speak of the adult and of the congenital (or infantile) varieties of hemiatrophy. The object of this report is to present a case and to discuss some pathological aspects of such congenital hemiatrophy.

The reduction in size of the brain in such cases is caused by loss of nerve tissue and its replacement by glial scars. The replacement is, in some cases, inadequate, and foci of acellular necrosis as well as cysts are frequently found. The larger cysts are usually filled with clear fluid, while the smaller ones may contain debris with fat and blood pigment phagocytes. Concomitant findings may include granular atrophy of gyri, ulegyria, status spongiosus, status marmoratus, thickening of blood vessels, mesenchymal proliferation, meningeal fibrosis, and hydrocephalus.

The extent and severity of the lesions are, by definition, more marked on one side, but the condition is seldom, if ever, strictly unilateral, some degree of scarring being also present in the second hemisphere. The basal ganglia may likewise be reduced in size on the affected side and this is accompanied by a crossed cerebellar atrophy. This association enabled Mott and Tredgold (1900) to deduce that such cerebellar atrophy depends on the involvement of the basal ganglia. Glial scars may also be found in the brain stem.

It was suggested by Schob (1930) that cerebral hemiatrophy comprises two distinct conditions: a variety of lobar scarring or ulegyria in which the lesions extend beyond a single lobe to affect a whole hemisphere and, secondly, progressive sclerosing hemiatrophy. Parenchymal loss is more uniform and usually less severe in the second condition, and the lesions are found chiefly in one of the cortical laminae, especially the third. Areas of focal destruction are uncommon. Blood pigment and fat-laden phagocytes are less numerous and are scattered more diffusely through the cortex, while the gliosis affects chiefly the digital white matter and is restricted in the cortex to its margin and the third lamina. Clinically, the condition is characterized by a more progressive mental deterioration and epilepsy. The existence of this distinct variety of hemiatrophy has been endorsed by Töppich (1935) and by Josephy (1945).

One of the earliest cases of cerebral hemiatrophy was reported by Charcot and Turner (1852). They found it in a mentally defective epileptic woman aged 20, and quoted Cazanviech and Calmiel as originators of the term 'atrophie ou agénesie cérébrale' which they themselves used to designate this condition. By 1861, when the Dutch anatomist Schroeder van der Kolk contributed a scholarly description of a case, which, in the manner of his time, was both long and detailed, there were already 29 similar cases on record. Later contributions included those of Howden (1875), Major (1879), Mott and Tredgold (1900). Köppen (1905), Spielmeyer (1906), Boyd (1912), Bielschowsky (1917), Stroh (1925), Brushfield and Wyatt (1927), Pekelsky (1932), Hassin (1935), Casamajor and Laidlow (1939), Alpers and Dear (1939), Liber (1940), Moore (1943), and Josephy (1945).

Most of the patients described in the literature have been mental defectives, others were cases of Little's disease, of hemiplegia, with or without extrapyramidal signs, and of epilepsy. Many cases have been diagnosed correctly during life and such diagnosis usually rested on the history, the neurological and psychiatric signs, and the radiological findings. The latter have been the subject of 
contributions by Dyke, Davidoff, and Masson (1933), Casamajor and Laidlow (1939), and by Ross (1941).

There is no reason, if one reserves temporarily the consideration of the so-called progressive sclerosing hemiatrophy, to discuss the aetiology of this condition separately from that of the large and varied group of sclerotic and cystic infantile encephalopathies, of which hemiatrophy is merely a topographical variant. The condition may be associated with the presence of true malformations such as microgyria pointing to an intra-uterine onset of at least part of the disorder. It may follow intra-uterine injury as in the case reported by Seitz (1907). Another form of hemiatrophy is associated with a haemangiomatous malformation of the meninges on the brain and may form a part of the Sturge-Weber syndrome. On the other hand, it may develop after birth, as in the case reported by Heubner (1882), where porencephaly was due to an embolus. In the case communicated by Stroh, hemiatrophy was caused by a subdural haematoma occurring as a result of infantile scurvy. Intrauterine infection as a possible aetiological agent has been discussed by Alpers and Patten (1936). The pathogenetic mechanisms leading to the formation of scars and cysts have also been the object of numerous contributions. Oedema was believed to be the chief mechanism involved by Hallervorden (1939), asphyxia by Courville (1950), anoxia due to a disturbance of the autonomic control of circulation by Rydberg (1932), venous thrombosis by Marburg and Casamajor (1944). A lytic ferment liberated from damaged myelin was suggested as a possible cause of cystic degeneration by Lumsden (1950).

It is necessary at this stage to refer to the opinion of Scholz (1933 and 1936), who thought that certain cerebral lesions might, in some cases, be the result of epilepsy. Such lesions could include diffuse or patchy gliosis, areas of loss of nerve cell and ulegyria, and may account for the ensuing mental deterioration. He did not, however, believe that areas of complete softening followed by the formation of cysts could be caused in this way. The opinion of Scholz has found some cautious support which was expressed by Meyer (1939) as follows:

\begin{abstract}
- Though this is certainly not the rule, it may be correct in certain otherwise obscure cases of infantile progressive mental and neurological deterioration with a long initial history of epilepsy and with post-mortem findings of the type described above.'
\end{abstract}

Ever since the publication of the classical paper by Little (1862) there has always been a current of opinion which regarded the processes of birth as an important factor in the causation of such infantile encephalopathies. A considerable number of morbid anatomical studies of neonatal and infantile brain material was undertaken by Schwartz (1924, 1927), Schwartz and Berberich (1924), Schwartz and Fink (1925), by Ylppö (1919), Siegmund (1923), and by Rydberg (1932). These contributions are of great importance since the authors traced the development of lesions from their earliest stages to the cystic and sclerotic brains, of which one is the subject of the present report. Schwartz has described the earliest lesions in the brain as either areas of haemorrhage, or softening, or of loosening (Auflockerung), and followed the subsequent formation of cysts and scars from these initial lesions. He came to the conclusion that most cerebral lesions of infancy, as well as such functional disturbances as asphyxia neonatorum, convulsions, infantile 'tetany', some cases of neonatal jaundice, and many extrapyramidal syndromes could be laid at the door of birth injury. He also suggested that much of the damage may be caused by congestion and haemorrhage from the radicles of the great vein of Galen, resulting from the differential pressure effect (Minderdruckwirkung) in the presenting head of the foetus produced by uterine contractions. The relation of prematurity to the incidence of cerebral damage at birth has been the subject of extensive investigations by Ylppö (1919) and by Wail (1950). The latter has been able to show that the argyrophil framework of cerebral blood vessels is incomplete and defective in immature infants, and that extravasations of blood may occur from them even without actual rupture. More recently, Rydberg has challenged some points of detail in Schwartz's observations, and stressed in his turn the importance of the functional disturbances in the nervous control of circulation and respiration at birth and the rôle of such disturbances in the production of cerebral lesions.

In a review of 130 necropsies of mental defectives Benda (1945) found that the cerebral damage could be attributed to birth injury in 24 cases. He also estimated that birth injury could be incriminated in $30 \%$ of idiots and in $8 \%$ of imbeciles. The contributions of Norman are also of considerable interest and importance. He has not only reviewed and summarized the latest work on the subject (Norman, 1950), but had himself previously reported cases of atrophic sclerosis of the cortex (Norman, 1944) and of état marbré of the corpus striatum (Norman, 1947) together with substantial clinical and pathological evidence favouring the natal origin of the brain damage in such cases.

It is extremely difficult to obtain a reliable history of preceding birth trauma in clinically diagnosed 
cases of encephalopathy. It is, furthermore, uncertain that a clinically difficult labour is necessarily associated with more severe brain injury. In a series of lumbar punctures performed in normal newborn infants Sharpe and Maclaire (1925) found frank blood in the cerebrospinal fluid in $7 \%$ to $13 \%$ of all their series of cases. Since haemorrhage is not the only possible brain lesion, and since haemorrhage in areas which do not adjoin the ventricular system or the subarachnoid space would not lead to the appearance of blood in the cerebrospinal fluid, the inference of these observations must be that cerebral damage in the newborn is very frequent. On the other hand Faber (1947) analysed 99 cases of children with established cerebral damage, and concluded from their histories that only $40 \%$ were due to natal causes. In an analysis of 618 neonatal deaths Agnes R. Macgregor (1946) has estimated that only $10.5 \%$ were due to developmental abnormalities, while intracranial haemorrhage accounted for $27.6 \%$ and asphyxia for $13.1 \%$ of cases. Experimental work is of limited value since the relative size of the human head at birth is so much larger than that of animals. The approach to this problem must of necessity remain analytical and depend, like that of Schwartz, Siegmund, and other workers on the deductive study of the brains of stillborn children and of children dying in early infancy.

The literature on the subject of brain injuries is very voluminous, but since much of it is both repetitive and speculative, it is possible to refer to the useful summaries provided by Ehrenfest (1922), Ford (1945), Bridge (1949), and Norman (1950). A valuable study of 400 cases of cerebral palsy was recently undertaken by Asher and Schonell (1950) in the Birmingham area. It may be said, however, that considerable confusion and unnecessary disagreement have been caused by the arbitrary definition of the term birth injury. Many workers, who have argued against the importance of birth injury, have interpreted the term in a purely mechanical sense as stretching or tearing. There is no real justification for such an attitude. The violent and complex process of birth involves many far-reaching functional and structural changes, of which the mechanical effects are only one component part.

It is also difficult to justify the attempts of many workers to incriminate one single reaction state like oedema, haemorrhage, tearing, or thrombosis as the sole or chief operative mechanism. These attempts can, perhaps, be partly explained by the implied belief held so commonly by biologists that the quality of interaction between the environment and the individual, of which such states are an expression, remains constant. If that were so it would indeed be reasonable to transpose an effect known to result at a certain stage of the individual's history to another, without gross error. The individual's ontogenesis is, however, not uniform. Stages of relatively gradual and stable development are punctuated by nodal points such as spermogenesis and ovulation, fertilization and birth, at which the quality of interaction between the individual and the environment is different. The significance of any single reaction state at any of these points must be assessed against a particularly rapid and violent complex of other changes. And since the biology of nodal points is at present so imperfectly understood it is unwise to interpret any of its isolated events in any stereotyped and preconceived way. What is pathological at one stage of ontogenesis may well be normal at nodal points and vice versa.

There is much meaning in the following remarks taken from Little's paper.

'There is, however, an epoch of existence, viz.
the period of birth, during which, at first sight, we
might consider that the foetal organism is subjected
to conditions so different to those of its earlier and
its prospective later existence, that any untoward
influences applied at this important juncture affect
the economy in a manner different to the influences
at work during the periods ordinarily characterized
as those before birth and after birth.'

It may be added that later observations and reflection did much to confirm Little's ' first sight.'

Events at nodal points must further be assessed against the background of the individual's past and future history. Birth trauma will tend to damage the larger head of the child of a diabetic mother more than that of an ordinary child. On the other hand, injury to the pyramidal tract at birth will only become apparent at a later age, when the pyramidal tracts begin to function fully. More hypothetically, it is possible to envisage a cortical lesion produced at birth, which only becomes epiloptogenic at an age when that part of the cortex, or areas surrounding it, would normally assume some of their full functional activity.

It must now be considered whether Schob's progressive sclerosing hemiatrophy can be reasonably separated from the remainder of the group of scarred and cystic brains. This can possibly be done to some advantage in the light of the examination of further cases of hemiatrophy, of which another example is reported below.

\section{Case Report}

The patient was a boy, admitted to the Fountain Hospital, London, at the age of 2 years and 7 months, who died two weeks later from bronchopneumonia. He was 


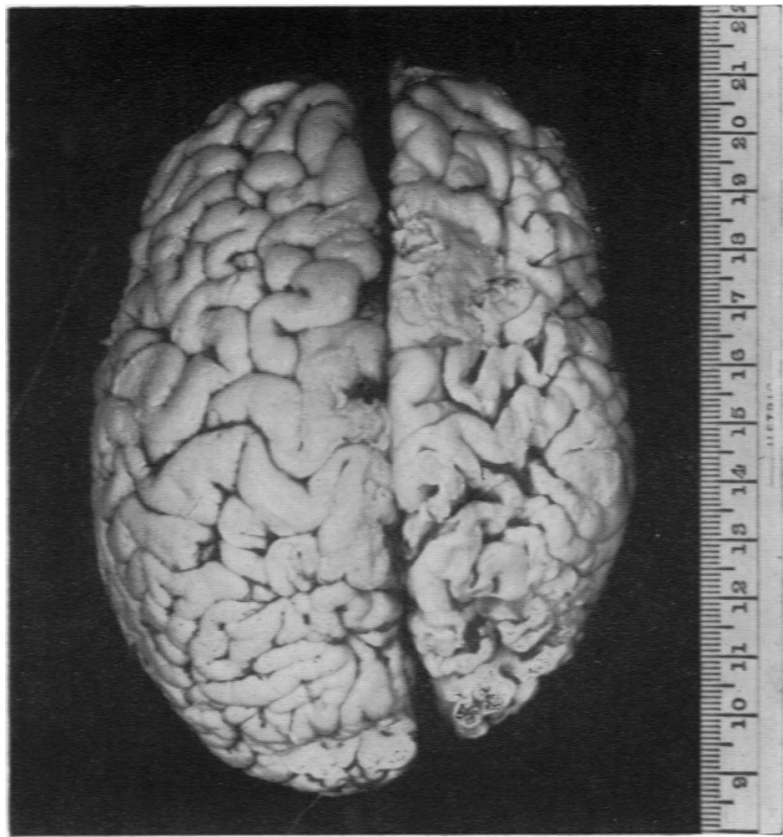

FIG. 1.-Dorsal view of the brain: right-sided hemiatrophy.

the second of three children- of healthy working-class parents with no history of mental or nervous trouble in the family, except for a 'nervous breakdown' in a maternal aunt. His older and younger brothers were both healthy. The patient was born after a normal pregnancy, but was five weeks premature. Delivery was said to be normal. His abnormality was first discovered when he had gastro-enteritis at the age of 5 weeks. He then had fits and was found to be blind. He never learned to walk or to talk.

On examination, his pupils reacted sluggishly to light and his left arm and right leg were spastic. He was incontinent and his hearing ability was doubtful. His attitude was restless and he was constantly making purposeless movements and noises. Convulsions were observed during his brief stay in hospital.

Post-mortem Findings. The only relevant findings, besides those in the central nervous system, were seen in the lungs which showed marked hypostatic oedema and a profuse watery mucoid exudate in the trachea and in the main and terminal bronchi.

Central Nervous System. The brain was small, weighing $680 \mathrm{~g}$. The dura was adherent to the vertex on the right side. The right hemisphere was $1 \mathrm{~cm}$. shorter than the left. The consistency of the brain was firm, cartilage-like over its posterior part. The gyri over most of the right hemisphere were narrow and the suki were widened. This appearance was also present in the left hemisphere, but the change there was confined to the occipital lobe. There was a marked depression in the parieto-occipital region over the vertex on the right side and the gyri in that depression showed granular atrophy. The pattern of the gyri was normal throughout the brain, but, in addition to the ulegyria, many of them in the posterior half contained numerous small cortical cysts.

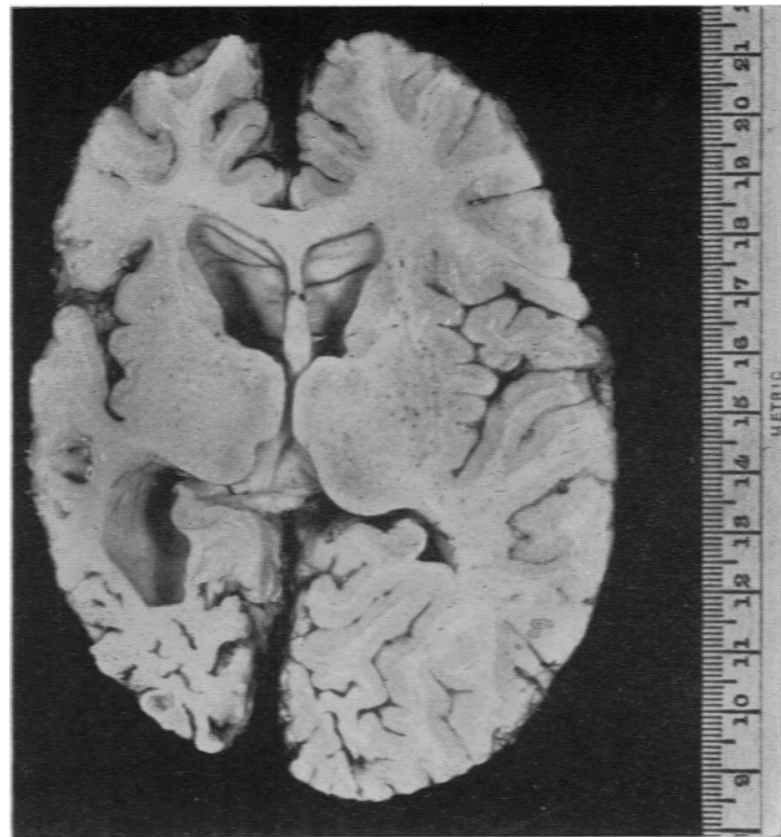

FIG. 2.-Horizontal section of the brain.

The largest of these cysts measured about $0.5 \mathrm{~cm}$. in diameter and the smallest were barely visible (Fig. 1).

A horizontal section through the whole brain showed that the firm white matter was ivory white. This white scarring was also seen in the putamen and in the thalamus on the right side. There was a moderate degree of internal hydrocephalus, similarly more marked on the right side (Fig. 2). All the structures of the brain stem appeared normal to the naked eye. The blood vessels and cranial nerves were normal.

Microscopy. Both hemispheres were divided into horizontal blocks and embedded in celloidin. Sections were also cut from representative blocks taken from the mid-brain, pons, medulla, and the cerebellum. The section's were stained with Heidenhain's haematoxylin for myelin; with thionin, Van Gieson, and Holzer's stain for fibrous glia. Frozen sections were stained for fat with Scarlet $\mathbf{R}$ and with Holzer's stain for fibrous glia.

The myelin sections confirmed the presence of ulegyria in the posterior parts of both hemispheres, which was more marked on the right side (Figs. 3 and 4). The forceps major and the digital white matter were greatly reduced in size. Status spongiosus and granular atrophy were present in several parts of the brain, especially in the cortex of the insula, and a marbled state of the myelin (plaques fibro-myéliniques) could be seen in some of the gyri covering the insula (Fig. 5). Both pyramidal tracts in the brain stem showed defective myelination and this was more marked on the right side.

Marked diffuse and focal cortical atrophy were the chief histological features. This was most marked on the right side, where, in the more severely affected places, it could be seen to involve indiscriminately all layers of the cortex. The areas of cell loss were in most cases replaced by glial scars (Fig. 6). Some of these areas had, 


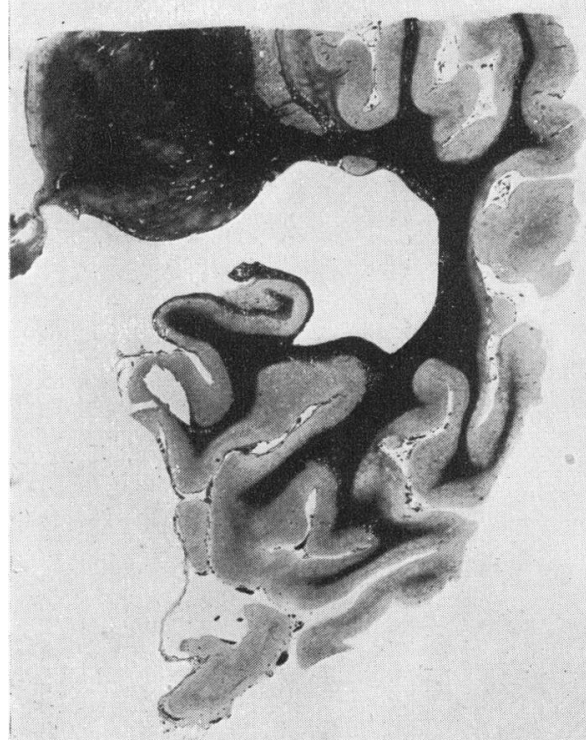

FIG. 3

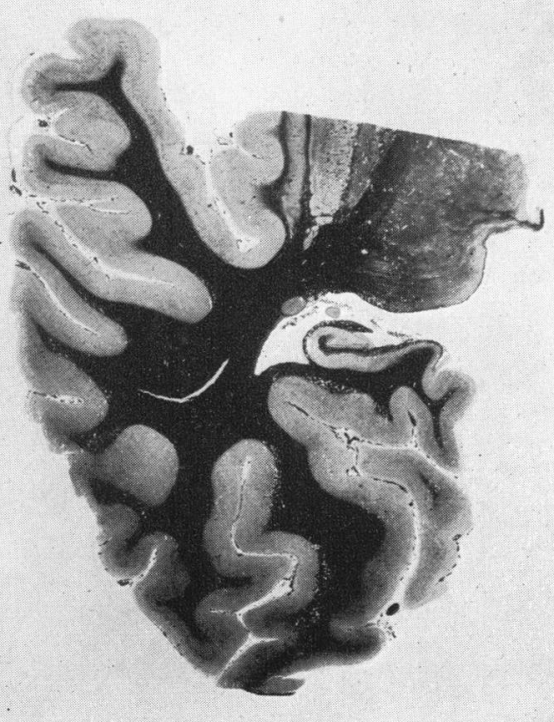

FIG. 4.
FIG. 3.-Posterior half of right hemisphere. Ulegyria.

FIG. 4.-Posterior half of left hemisphere.

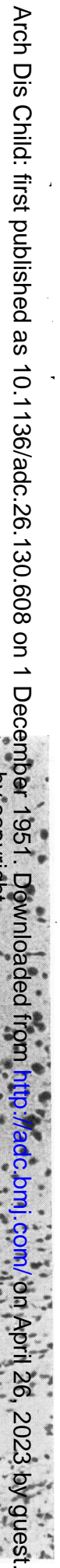

FIG. 6- Junction of cortex and glial scar. Thionin $\times 18 \theta_{0}$

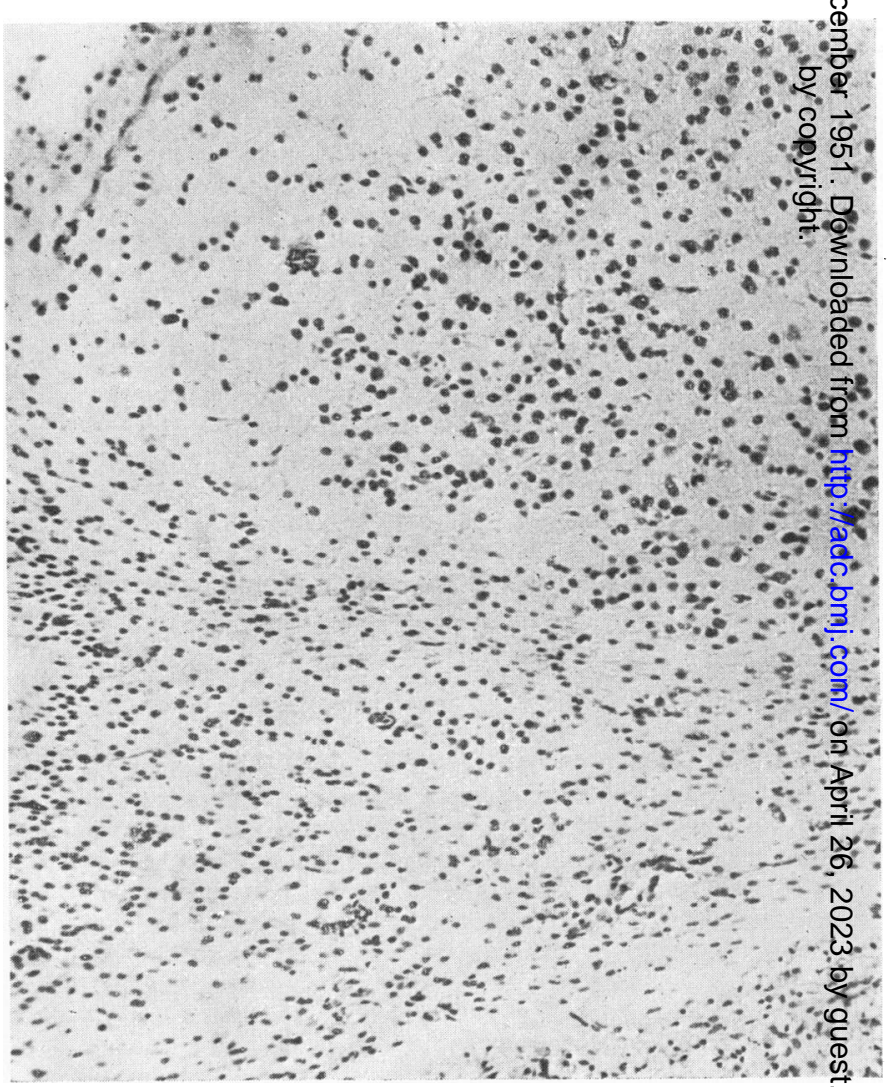

웅
$\stackrel{\frac{9}{\mathbb{D}}}{\mathrm{D}}$

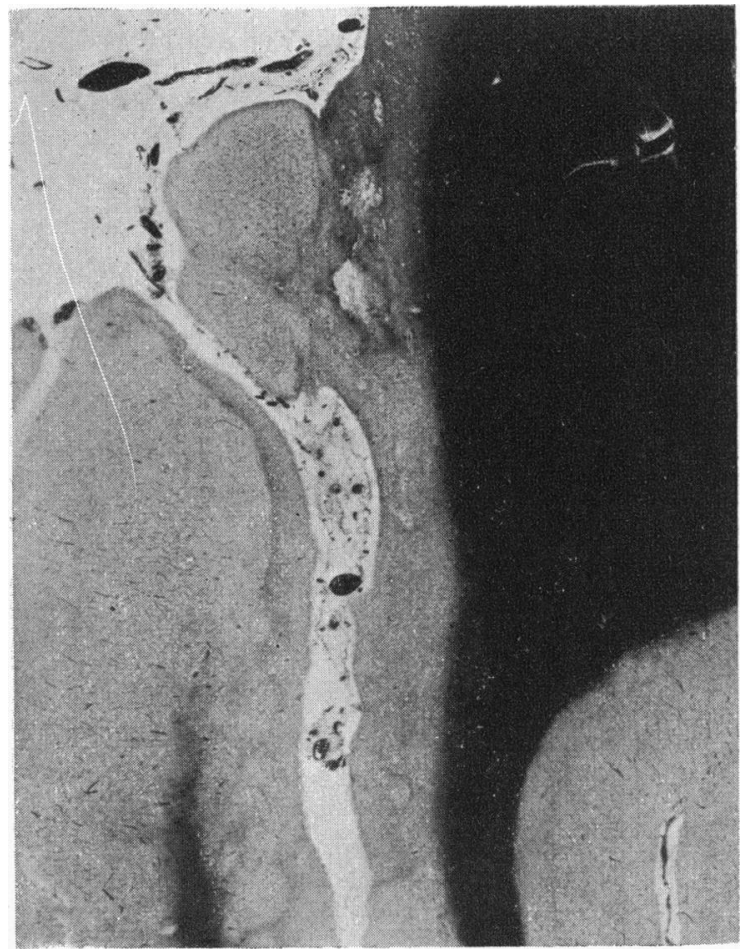

Fig. 5.-Status spongiosus, granular atrophy, and plaques fibro-myélinques. Heidenhain's myelin stain $\times 14 \cdot 5$. 


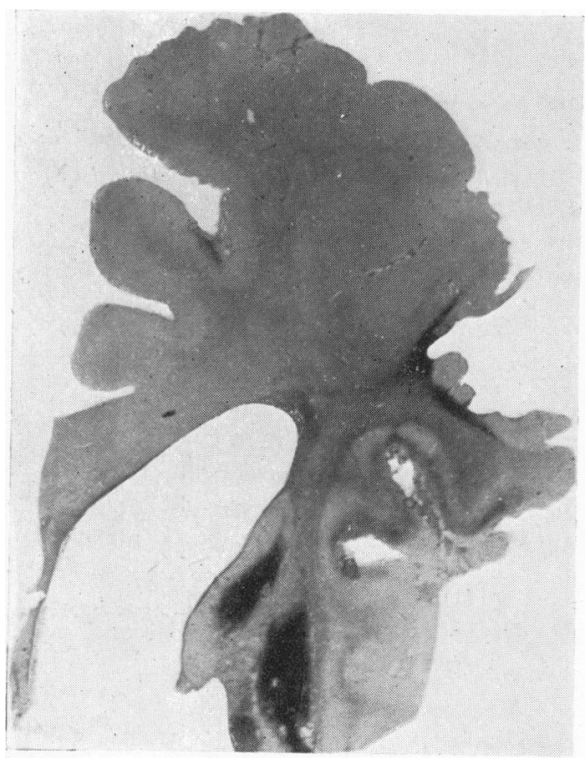

FIG. 7.-Gliosis affecting chiefly the corpus striatum. Holzer stain.

FIG. 8.-Fat in cystic and perivascular spaces. Scarlet $\mathbf{R}$ and haematoxylin $\times 280$.

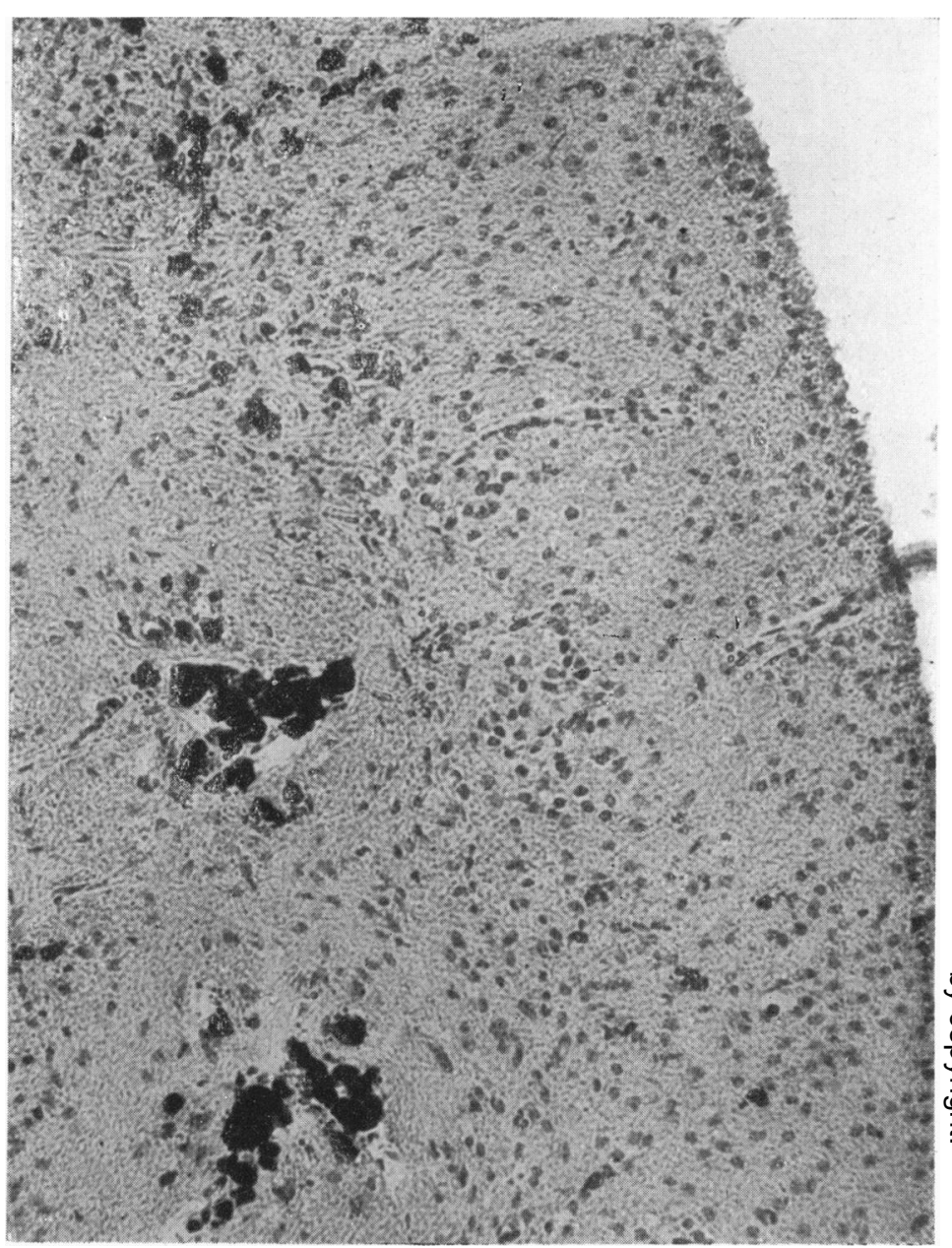

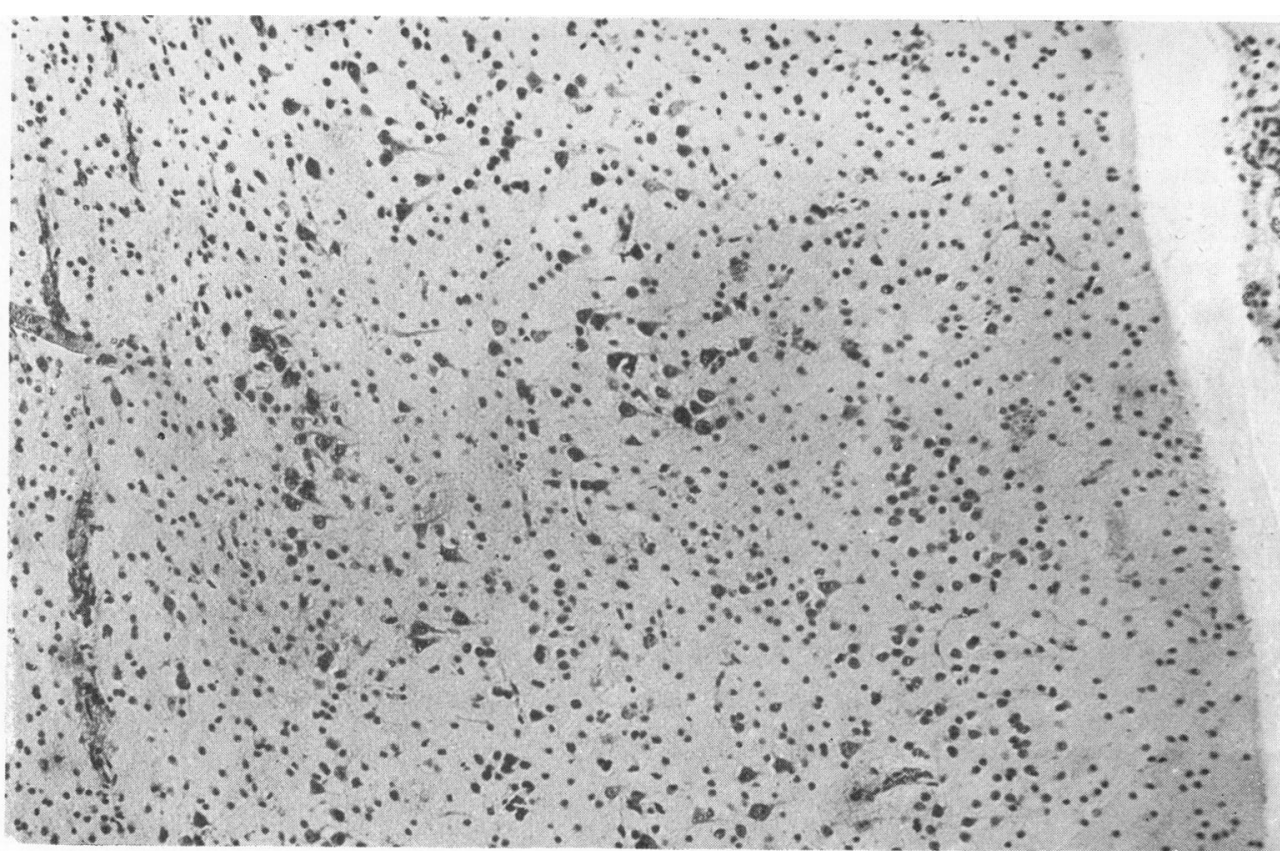

Fig. 9.-Cortex on left side. Loss of nerve cells. Numerous 'ghost' cells are present. Thionin $\times 180$. 
however, remained unrepaired, and a few compound granular corpuscles and blood pigment-containing phagocytes could be seen lying in or near their centre. The transition between areas of cell loss and the more normal cortex was always gradual. Many of the nerve cells in the transitional zones showed varying degrees of degenerative change. In the more normal parts of the cortex, and particularly on the left side, the loss of nerve cells was much more uniform and tended to be systematized affecting one of the laminae, especially the third (Fig. 9). The basal ganglia were also affected. Almost all the cells of the putamen and those in a large part of the caudate nucleus on the right side had disappeared and were replaced by fibrous glia. In addition there were smaller focal lesions in the thalamus. Section from the cerebellum showed some loss of nerve cells and an increase of glia in the dentate nuclei.

Examination of sections stained for fibrous glia showed dense gliosis of both cortex and the white matter of the cerebrum. This gliosis was not uniform. In places it was confined to the white matter stopping short of the cortex. In other places it affected the cortex also. Numerous microcysts and larger cystic cavities were seen in the gliosed areas. The gliosis of the basal ganglia on the right side corresponded to the areas of cell loss described above (Fig. 7). There was also marginal, peri-aqueductal, and periventricular gliosis in the brain stem and in the area of the dentate nuclei of the cerebellum.

Sections stained for fat showed numerous fat-laden phagocytes in the cortex on the more affected side. These were distributed both diffusely and in dense foci round blood vessels and in the smaller cysts (Fig. 8). In the less affected areas, particularly on the left side, fat cells were distributed less densely and more uniformly throughout the cortex.

In addition there was some fibrosis of the leptomeninges and thickening of some of the cortical blood vessels. No thrombi were found in them.

\section{Discussion}

The character and distribution of the lesions in this case indicate the end-result of destructive processes. The general picture closely resembles that shown by Schwartz and by Siegmund to follow birth injuries. The history of prematurity and the known association of such prematurity with an increased incidence of brain damage further support this conclusion. The predominantly posterior localization of the lesions and their topographical systematization in the basal ganglia is in agreement with the suggestion made by several workers in the past regarding the vulnerability of the radicles of the vein of Galen to birth injuries.

While the focal character of many lesions and the abundance of fat-laden cells place this case in the group of lobar ulegyria, there are also many lesions in it, particularly in the less affected areas of the brain, which correspond to those described in the progressive sclerosing variety of hemiatrophy. It seems possible that the more insidious and uniform changes found in the latter condition could be the result of less severe initial lesions and a more protracted course. Further case material is therefore desirable in order to establish the validity of its nosological entity.

\section{Summary}

The literature relating to hemiatrophy of the brain is reviewed and its possible aetiology discussed. A case of hemiatrophy is reported and it is suggested that it followed birth injury associated with prematurity. The nosological position of progressive sclerosing hemiatrophy of Schob is also discussed.

I wish to thank Professor A. Meyer for his advice and helpful criticism.

\section{REFERENCES}

Alpers, B. J., and Dear, R. B. (1939). J. nerv. ment. Dis., $89,653$.

and Patten, C. A. (1936). Amer. J. Dis. Child., $52,144$.

Asher, P., and Schonell, F. E. (1950). Archives of Disease in Childhood, 25, 360.

Benda, C. E. (1945). Medicine, 24, 71.

Bielschowsky, M. (1917). J. Psychol. Neurol., Lpz., 22, 225.

Boyd, W. (1912). Rev. Neurol. Psychiat., 10, 318.

Bridge, E. M. (1949). "Epilepsy and Convulsive Disorders in Children,' p. 45. New York and London.

Brushfield, T., and Wyatt, W. (1927). Rep. metrop. Asylums Bd. (1926-27), 29, 295.

Casamajor, L., and Laidlaw, R. W. (1939). Amer. J. Psychiat., 96, 165.

Charcot, J. M. and Turner, T. E. (1852). C.R. Soc. Biol., Paris, 4, 191.

Courville, C. B. (1950). Bull. Los Angeles neurol. Soc., $15,155$.

Dyke, C. G., Davidoff, L. M., and Masson, C. B. (1933). Surg. Gynec. Obstet., 57, 588.

Ehrenfest, H. (1922). 'Gynecological and Obstetrical Monographs,' vol. 6. New York.

Faber, H. K. (1947). Amer. J. Dis. Child., 74, 1.

Ford, F. R. (1945). 'Diseases of the Nervous System in Infancy, Childhood and Adolescence,' 2nd ed., p. 876. Springfield, Illinois.

Hallervorden, J. (1939). Psychiat.-neurol. Wschr., 41, 25. Hassin, G. B. (1935). Arch. Neurol. Psychiat., Chicago, 33, 917.

Heubner (1882). Berl. klin. Wschr., 19, 737.

Hoestermann, E. (1912). Arch. Psychiat. Nervenkr., 49, 40 .

Howden, J. C. (1875). J. Anat., Lond., 9, 288.

Josephy, H. (1945). J. Neuropath. exp. Neurol., 4, 250.

Köppen, M. (1905). Arch. Psychiat. Nervenkr., 40, 1.

Liber, A. F. (1940). Arch. Neurol. Psychiat., Chicago, 43, 841 .

Little, W. J. (1862). Trans. obstet. Soc. Lond., 3, 293.

Lumsden, C. E. (1950). J. Neuropath. exp. Neurol., 9, 119. Major, H. C. (1879): J. ment. Sci., 25, 161.

Macgregor, A. R. (1946). Brit. med. Bull., 4, 174.

Marburg, O., and Casamajor, L. (1944). Arch. Neurol. Psychiat., Chicago, 52, 170. 
Meyer, A. (1939). J. ment. Sci., 85, 927.

Moore, J. (1943). J. nerv. ment. Dis., 98, 31.

Mott, F. W., and Tredgold, A. F. (1900). Brain, 23, 239.

Norman, R. M. (1944). Archives of Disease in Childhood, $19,111$.

(1947). J. Neurol. Neurosurg. Psychiat., 10, 12. (1950). In 'Recent Progress in Psychiatry,' 2nd ed., p. 324. London.

Pekelsky, A. (1932). Arb. neurol. Inst. (Inst. Anat. Psychiol. Zent Nerv.) Univ. Wien., 34, 221.

Ross, A. T. (1941). Amer. J. Roentgenol., 45, 332.

Rydberg, E. (1932). Acta path. microbiol. scand., Supp. 10.

Schob, F. (1930). 'Die Anatomie der Psychosen,' p. 929 . Berlin.

Scholz, W. (1933). Z. ges. Neurol. Psychiat., 145, 471. (1936). Allg. Z. Psychiat., 104, 89.
Schroeder van der Kolk, J. L. C. (1861). In 'Selected monographs,' New Sydenham Soc., vol. 11, p. 129.

Schwartz, P. (1924). Z. ges. Neurol. Psychiat., 90, 263. (1927). Ergebn. inn. Med. Kinderheilk., 31, 165.

- , and Berberich (1924). Zbl. allg. Path. Path. Anat., 34,621 .

$\longrightarrow$, and Fink, L. (1925). $\quad Z$. Kinderheilk., 40, 427.

Seitz, L. (1907). Arch. Gynaek., 83, 701.

Sharpe, W., and Maclaire, A. S. (1925). J. Obstet. Gynaec., Brit. Emp., 32, 79.

Siegmund, H. (1923). Virchows Arch., 241, 237.

Spielmeyer, W. (1906). Münch. med. Wschr., 53, 1404.

Stroh, H. (1925). Z. ges. Neurol. Psychiat., 99, 1.

Töppich, G. (1935). Arch. Psychiat., Nervenkr., 103, 335.

Wail, S. S. (1950). Arkh. Patol., 12, No. 2, p. 38.

Ylppö, A. (1919). $\quad Z$. Kinderheilk., 20, 212. 